\title{
Hardware and Instrumentation to Investigate Massive Releases of Dense Phase $\mathrm{CO}_{2}$
}

\author{
$\underline{\text { Didier JAMOIS }}^{\mathrm{a}}$, Christophe PROUST ${ }^{\mathrm{ab}}$, Jérome HEBRARD ${ }^{\mathrm{a}}$, \\ ${ }^{a}$ INERIS, BP2, 60550 Verneuil en Halatte \\ ${ }^{\mathrm{b}}$ UTC Laboratoire TIMR EA4297, Centre Pierre Guillaumat, 60200 Compiègne
}

\begin{abstract}
CCS is seen as a possibility to mitigate the global warming effect. The practical implementation of this technique faces a few challenges like safety issues. It is wondered if a massive release affecting the pipeline (may be the most vulnerable part of the CCS chain) would not lead to a disaster remembering what happened in Africa about 28 years ago (about Nyos Lake accident see Eos, 2009). Few experimental observations of large-scale $\mathrm{CO}_{2}$ releases have been made, and the physics and thermochemistry involved are not fully understood, even if considerable progress has been made theoretically [2]. In this paper, the experimental techniques used to investigate this specific problem are described and illustrated with some key results extracted from various projects. Innovative techniques were employed to control the mass flowrate, blowdown, near field and far field dispersion in the atmosphere. A 2 $\mathrm{m}^{3}$ spherical vessel able to store up to $1000 \mathrm{~kg}$ of $\mathrm{CO}_{2}$ at a pressure above $8 \mathrm{MPa}$ was used. Dense $\mathrm{CO}_{2}$ was allowed to spill out via a $50 \mathrm{~mm}$ pipe. The temperature, $\mathrm{CO}_{2}$ concentration and density field of the outside cloud were monitored using thermocouples and concentration probes. Among other results, it was in particular shown that when the mass flowrate is large enough, body forces become significant forcing the cloud to stay on the ground.
\end{abstract}

\section{Keywords}

$\mathrm{CCS}, \mathrm{CO}_{2}$, multi-phase flow, experimental measurement, pipeline depressurization

\section{Introduction}

$\mathrm{CO}_{2}$ accumulation in the atmosphere due to energy production systems using fossil fuels is widely considered responsible for global warming. A short or medium term solution is currently proposed involving capturing $\mathrm{CO}_{2}$ inside the combustion products at the source (or extract it from the fuel before combustion), then conveying $\mathrm{CO}_{2}$ to geological storages. These technologies are known as CCS (Carbon capture and storage). In most planned CCS projects, $\mathrm{CO}_{2}$ is transported from the capturing points to the storage sites using high-pressure pipelines, operating typically above 8 $\mathrm{MPa}$. In these transportation conditions, $\mathrm{CO}_{2}$ is in a dense phase either in the supercritical state (if the temperature is above $304 \mathrm{~K}$ ) or as a liquid state.

The practical implementation, however, raises many difficulties including safety issues in case of pipeline failure. $\mathrm{CO}_{2}$ is a colourless and odourless gas under ambient conditions but is toxic if the concentration in air is above $5 \%$, and fatality is possible above $10 \%$ (NIOSH, 1996). Further, the $\mathrm{CO}_{2}$ Joule-Thomson expansion coefficient is high so that release temperatures may fall below $-80^{\circ} \mathrm{C}$ rendering possible the 
formation of a solid phase. Consequently, $\mathrm{CO}_{2}$ spillage would produce clouds much denser than air, due to $\mathrm{CO}_{2}$ high molecular mass and very low temperature. A densitydriven flow of the cloud is expected which would maintain the cloud on the ground, accumulates in low-lying areas and stays there for a long time increasing the risk to humans.

It is therefore of primary importance to be able to address experimentally these physical aspects in order to develop and validate mathematical models for predicting the accidental blowdown of a pipeline and the subsequent formation of the cloud [4] [5]. Unfortunately, only very limited data sets on $\mathrm{CO}_{2}$ release are available [6] [7] [8]. This paper describes a relatively large scale $\mathrm{CO}_{2}$ release experimental device developed to investigate the flow regimes and the subsequent cloud resulting from the blowdown of a high pressure $\mathrm{CO}_{2}$ reservoir. Some key results are presented. They were obtained from various projects including E.U. funded CO2PipeHaz.

\section{$2 \mathrm{CO}_{2}$ reservoir and release device}

The centrepiece of the experimental setup is an existing highly insulated high pressure vessel used as a $\mathrm{CO}_{2}$ buffer reservoir $\left(2 \mathrm{~m}^{3}, 20 \mathrm{MPa}, 200^{\circ} \mathrm{C}\right.$ max : Figure 1). The top flange (in red on Figure 1) supports a vertical rod on which 5 thermocouples are attached (K type protected by a $2 \mathrm{~mm}$ steel sleeve pointing in the fluid at $3 \mathrm{~mm}$ away from the rod). Another flange (in green on Figure 1) is equipped with a 50mm hole prolonged internally with a $50 \mathrm{~mm}$ diameter and 1.60 meter long curved pipe plunging at the bottom of the sphere. This way, liquid $\mathrm{CO}_{2}$ is pushed into the pipe as long as the depth of the liquid phase is more than 50 to $100 \mathrm{~mm}$. For safety reasons (to accommodate pressure variation in case of a temperature excursion), the maximum quantity of $\mathrm{CO}_{2}$ is limited to $1000 \mathrm{~kg}$.
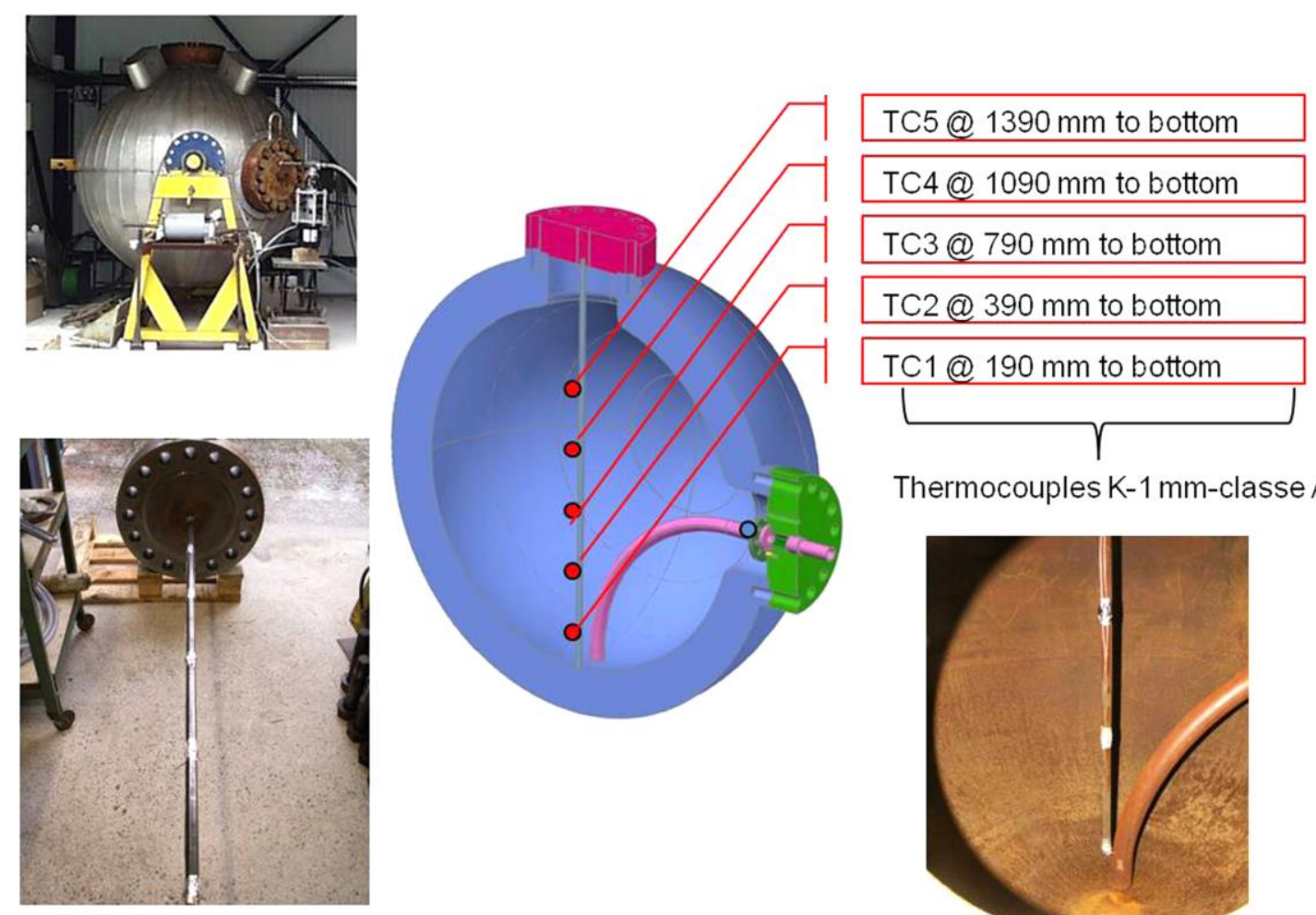

Thermocouples K-1 mm-classe A

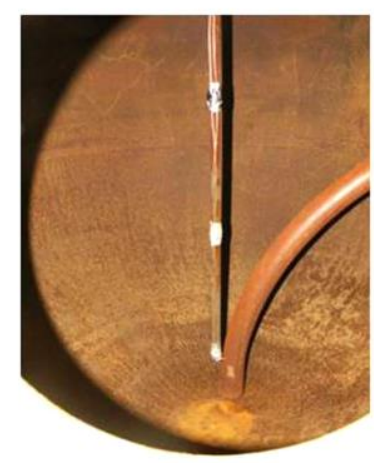

Figure 1 : the $2 \mathrm{~m}^{3}$ test reservoir and internal arrangement of the piping 
The internal pressure is monitored using two pressure transducers set on a third flange (piezoresistive KISTLER type 4045 A 200; 0 - $20 \mathrm{MPa} \pm$ 0,02 MPa).

A typical example of pressure/temperature measurements inside the sphere is presented in Figure 2 (22 seconds release through a $9 \mathrm{~mm}$ diameter hole - details concerning the pipe arrangement are given later). Looking at the conditions before the start of the release, the temperature is not homogeneous because of the history of the filling of the reservoir (several $\mathrm{CO}_{2}$ commercial tanks are emptied in the vessel and they may not stand at the same temperature). In this particular case, each phase (vapour and liquid) seems thermally homogeneous but the temperature of the liquid is different from that of the vapour. TC3 should not be far from the interface because the temperature is intermediate. A further indication appears during the discharge, when the vapour-liquid interface reaches TC3 location, the temperature drops from the liquid to the vapour temperature level. Temperature variations around the mean curve are typically $\pm 0.4^{\circ} \mathrm{C}$ in conformity with the category of these thermocouples (class A).

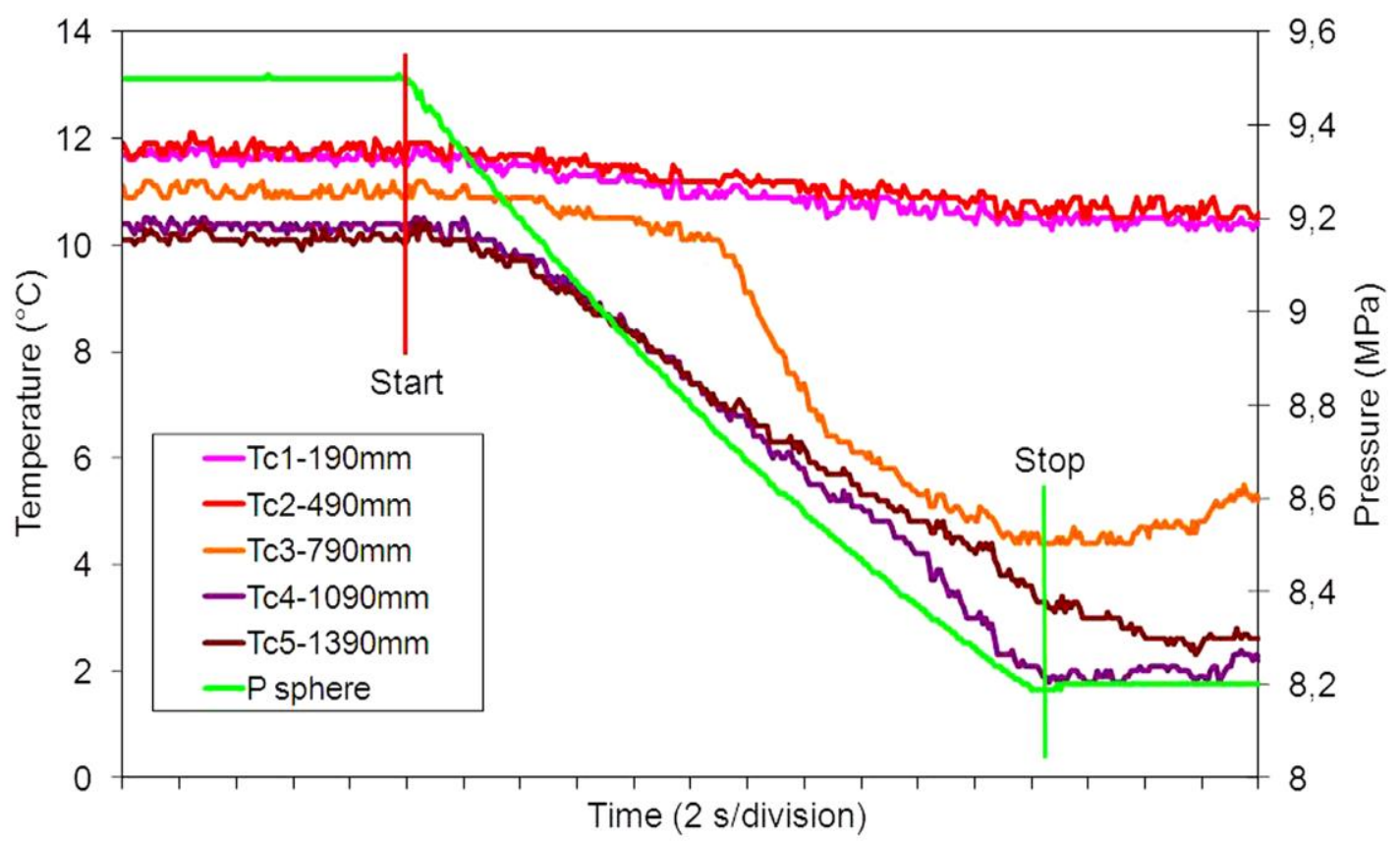

Figure 2 : Example of temperature and pressure measurement in the sphere before, after and during a discharge. "Start" indicates the opening of the release valve and "Stop" its closure.

The inner $50 \mathrm{~mm}$ curved section of pipe is extended outside (figure 3) with a pipe/valves arrangement with the same inner diameter (nominal pressure $15 \mathrm{MPa}$ ) all along, except at the very end. Two successive isolation valves are installed next to the vessel flange (one manual one remotely actuated). The total length of the pipe (including the inner section) is set to $6 \mathrm{~m}$, but can be extended for specific concerns (release direction, impact of length on physics of release). Close to the release end, a third isolation valve (remotely actuated) is mounted, just upstream of the orifice holder. The orifice holder is a large screw with calibrated holes (from 6 to 25mm). The release end can be used without the screw in order to perform full bore releases. 


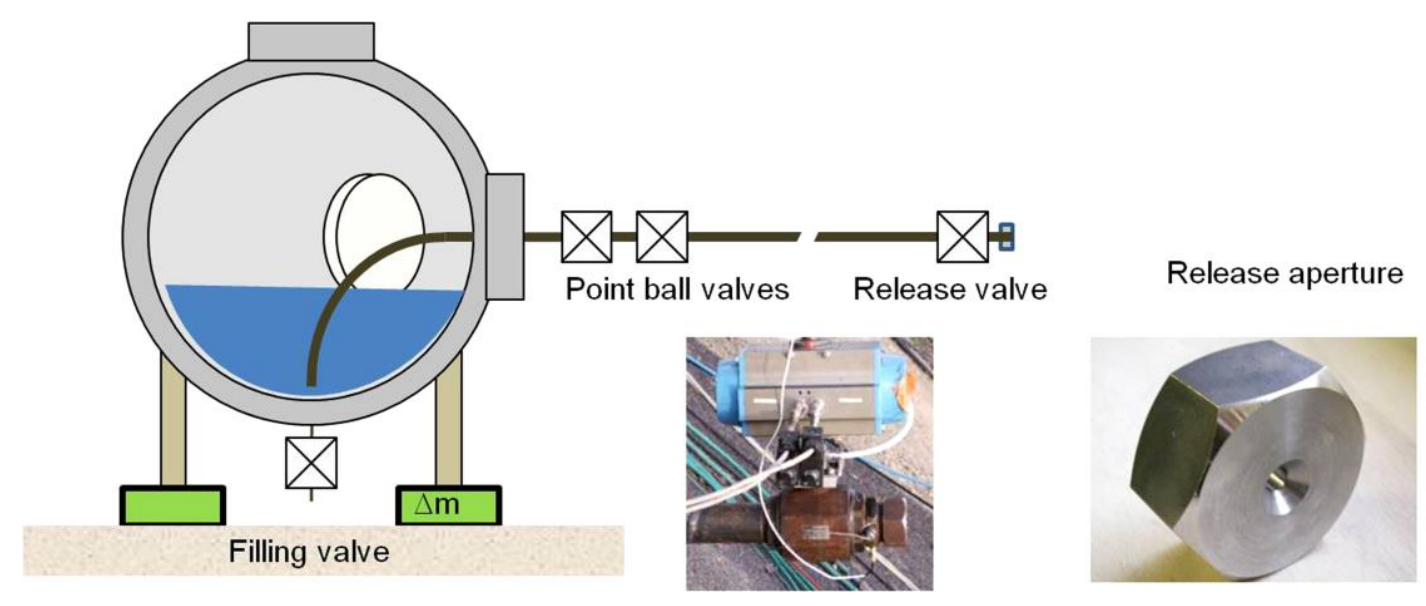

Figure 3 : sketch and photographs of the vessel/pipe arrangement

A pressure sensor (KULITE $0-35 \mathrm{MPa} \pm 0,3$ ) and a thermocouple ( $\mathrm{K}$ type in a steel sleeve, $1 \mathrm{~mm}$, class A) are positioned few millimetres upstream the orifice. A typical example of signals is presented on Figure 4. The $\mathrm{CO}_{2}$ temperature in the vessel may be different from ambient (which is the initial temperature of the pipe). In the specific conditions of this test $\left(12 \mathrm{~mm}\right.$ diameter, pressurised liquid $\left.\mathrm{CO}_{2}\right)$ the pressure inside the sphere (P volume) and that measured at the orifice ( $\mathrm{P}$ release) are extremely close suggesting a very small effect of head losses. The temperature signals at the bottom of the vessel and upstream from the orifice look very similar too, suggesting the fluid is not flashing and that heat losses to the surroundings seem to play only a small role.

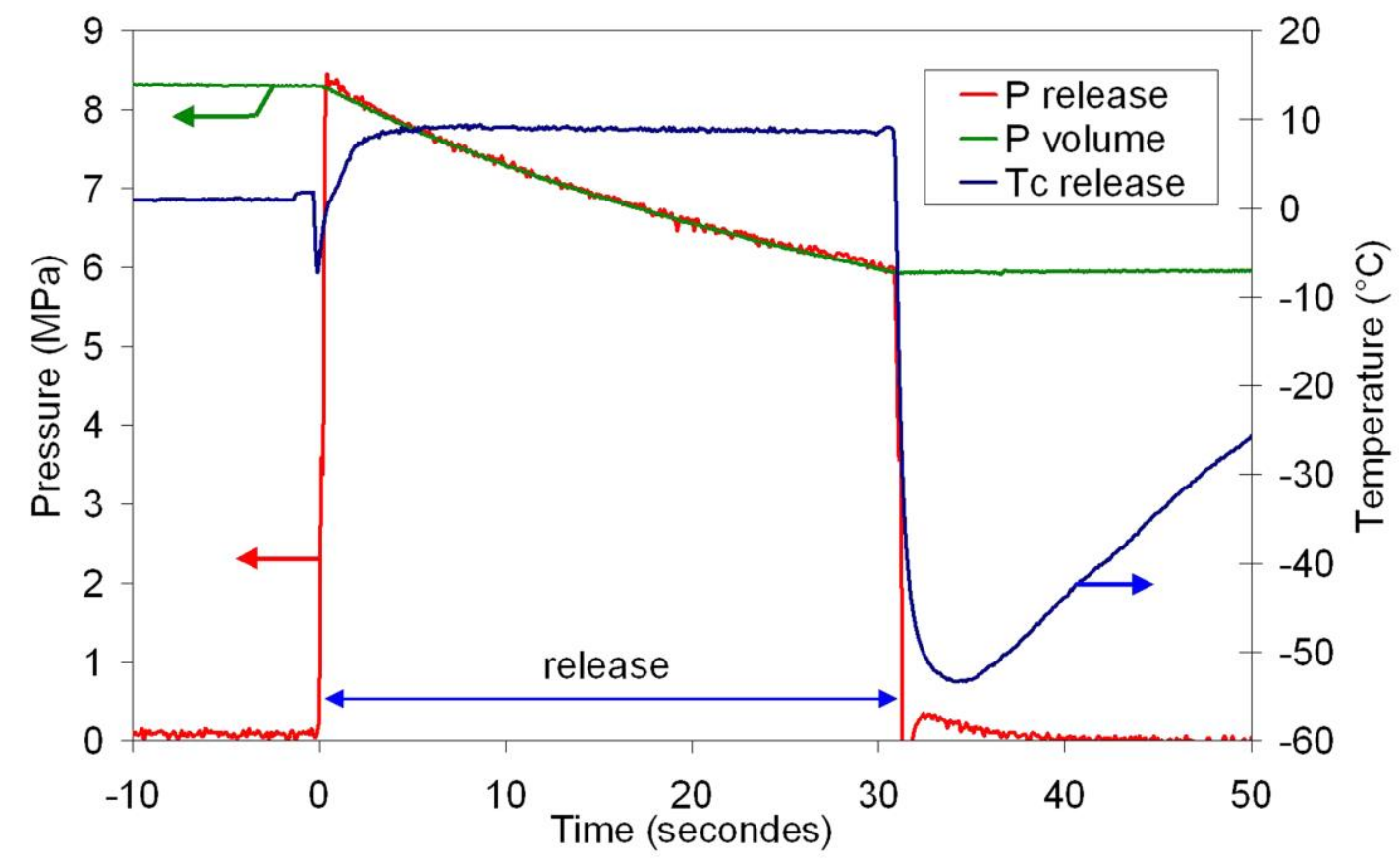

Figure 4 : Example of temperature and pressure signals obtained at the orifice (12mm diameter)

The vessel is laid on 4 electronic weighting pads (METTLER TOLEDO 250-2000 kg $\pm 1 \mathrm{~kg})$ to control the evolution of the content of $\mathrm{CO}_{2}\left(\mathrm{M}_{\mathrm{CO} 2}\right)$ during filling operations and releases. A typical example is presented on Figure 5. When the decrease of mass is more than $50 \mathrm{~kg}$, the error on the mean mass flowrate is not greater than $\pm 5 \%$. For large spills of $\mathrm{CO}_{2}$ (either long releases or large orifices), the mass flowrate may not stay constant as Pvolume decreases. By deriving $\mathrm{M}_{\mathrm{CO} 2}$ as function of time, the 
instantaneous mass flowrate can be obtained. The experimental error is about $\pm 10 \%$ when the raw signal is averaged over 10 data points (representing a duration of $1 \mathrm{~s}$ for a data acquisition rate of $10 \mathrm{~Hz}$ ).

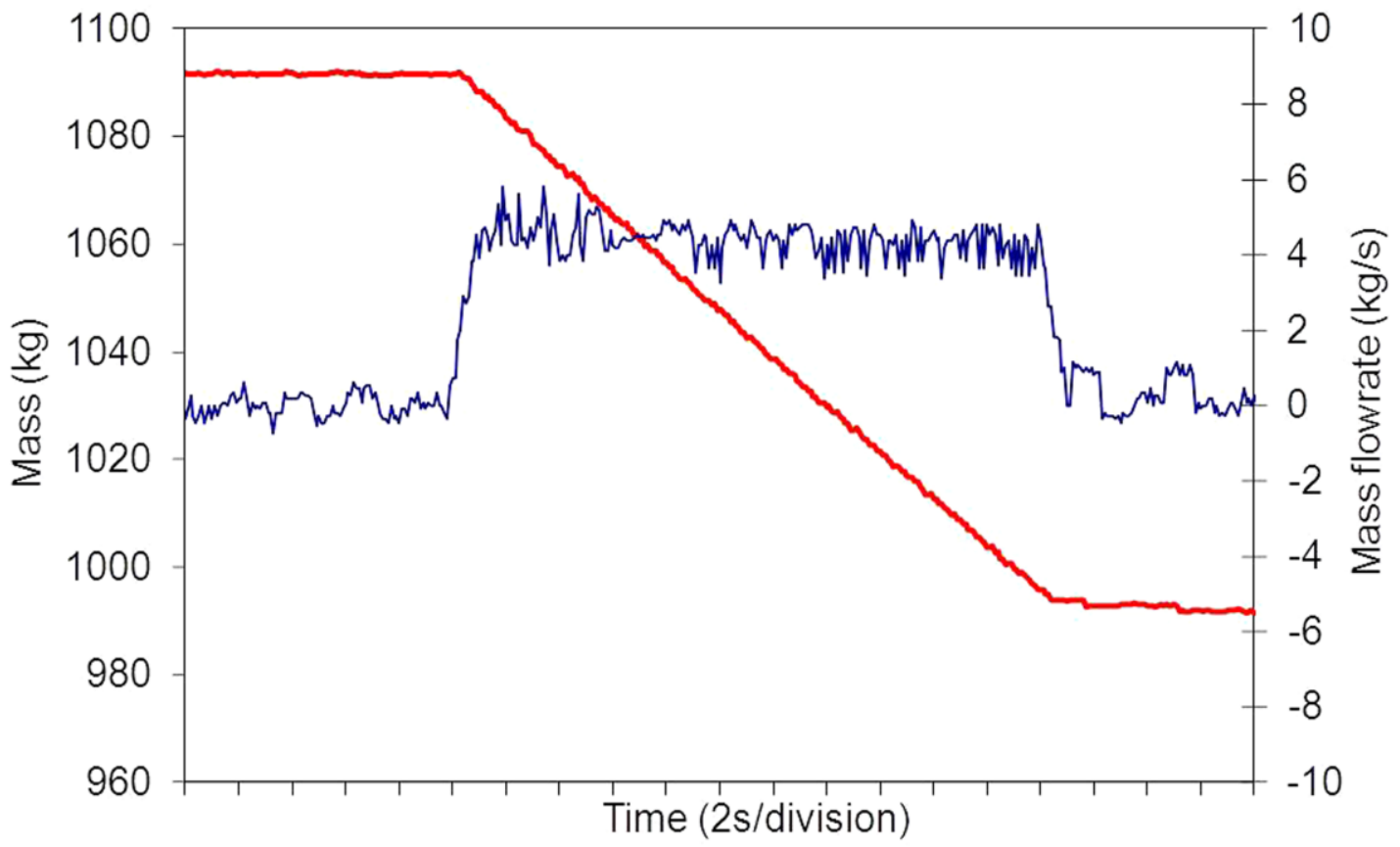

Figure 5 : Example of mass lost from the sphere during a release (red curve) and instantaneous mass flowrate calculation (blue curve) - Initial pressure : 9.5 MPa, Release diameter : 9mm

Results of several experiments are presented on Figure 6 when $\mathrm{CO}_{2}$ is stored (and released) at the saturation conditions in the vessel. Different orifice sizes were used. The mass flowrate is proportional to cross section (the red curve fits the diameter square) of the orifice except for the full bore opening. In this latter case, very significant head losses and liquid flashing were observed.

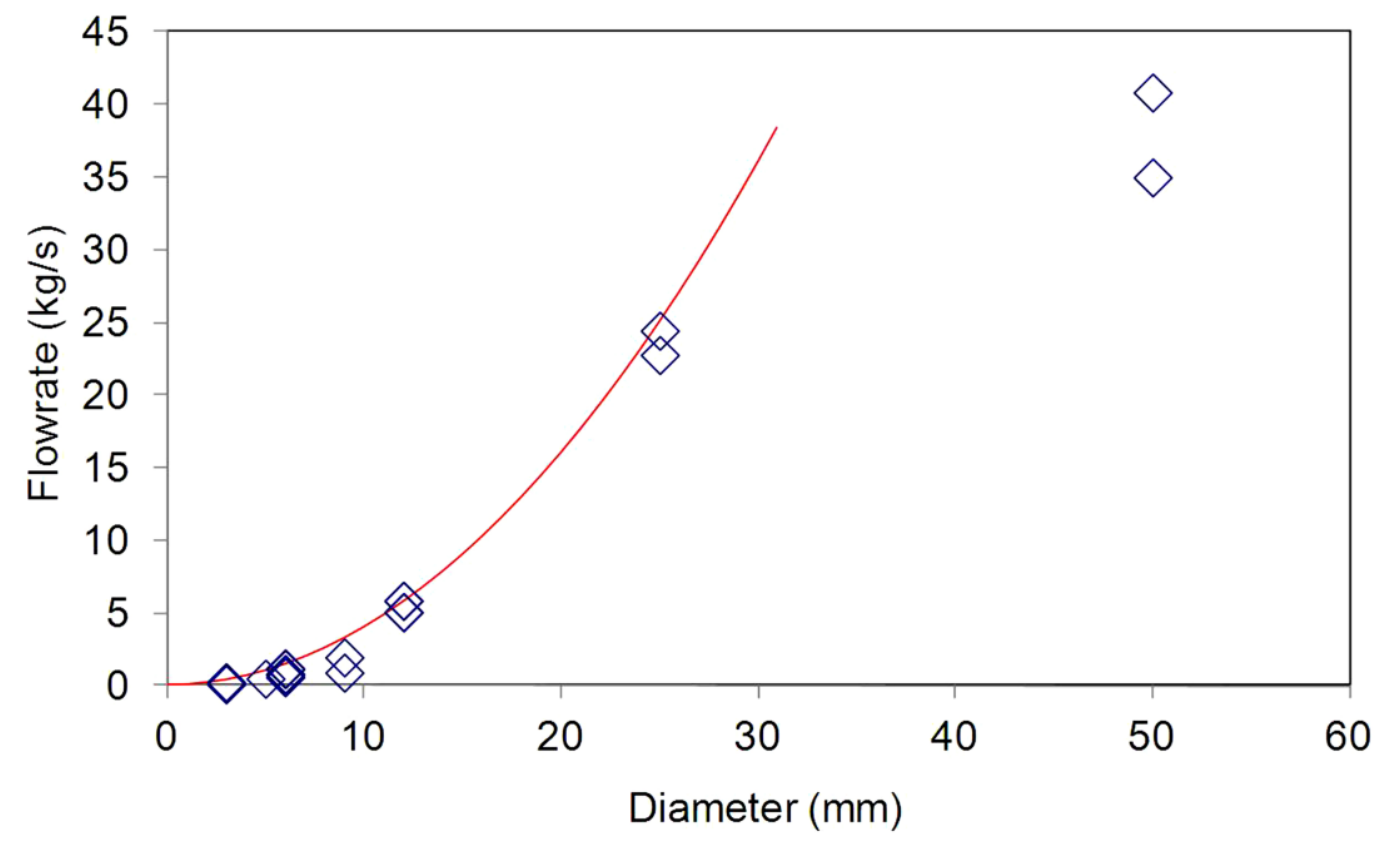

Figure 6 : Flowrate versus release diameter for different releases at vapour-liquid equilibrium 
At ambient conditions $\left(20^{\circ} \mathrm{C}\right), \mathrm{CO}_{2}$ is mostly liquid in the sphere with a vapor pressure of about $5 \mathrm{MPa}$. As it was planned to realize tests with a driving pressure of up to $12 \mathrm{MPa}$ (see figure 7 for the different test conditions studied up to now), helium was used to pressurize. Obviously helium can be dissolved into the liquid but we observed that a strong stratification establishes inside the reservoir. We can control the concentration of helium in $\mathrm{CO}_{2}$ in the liquid phase before and after every test with an analyzer (chromatograph with catharometric detector from Agilent) by sampling the liquid phase in the pipe. We admit a threshold of $1 \%$ in mass as a limit for the test.

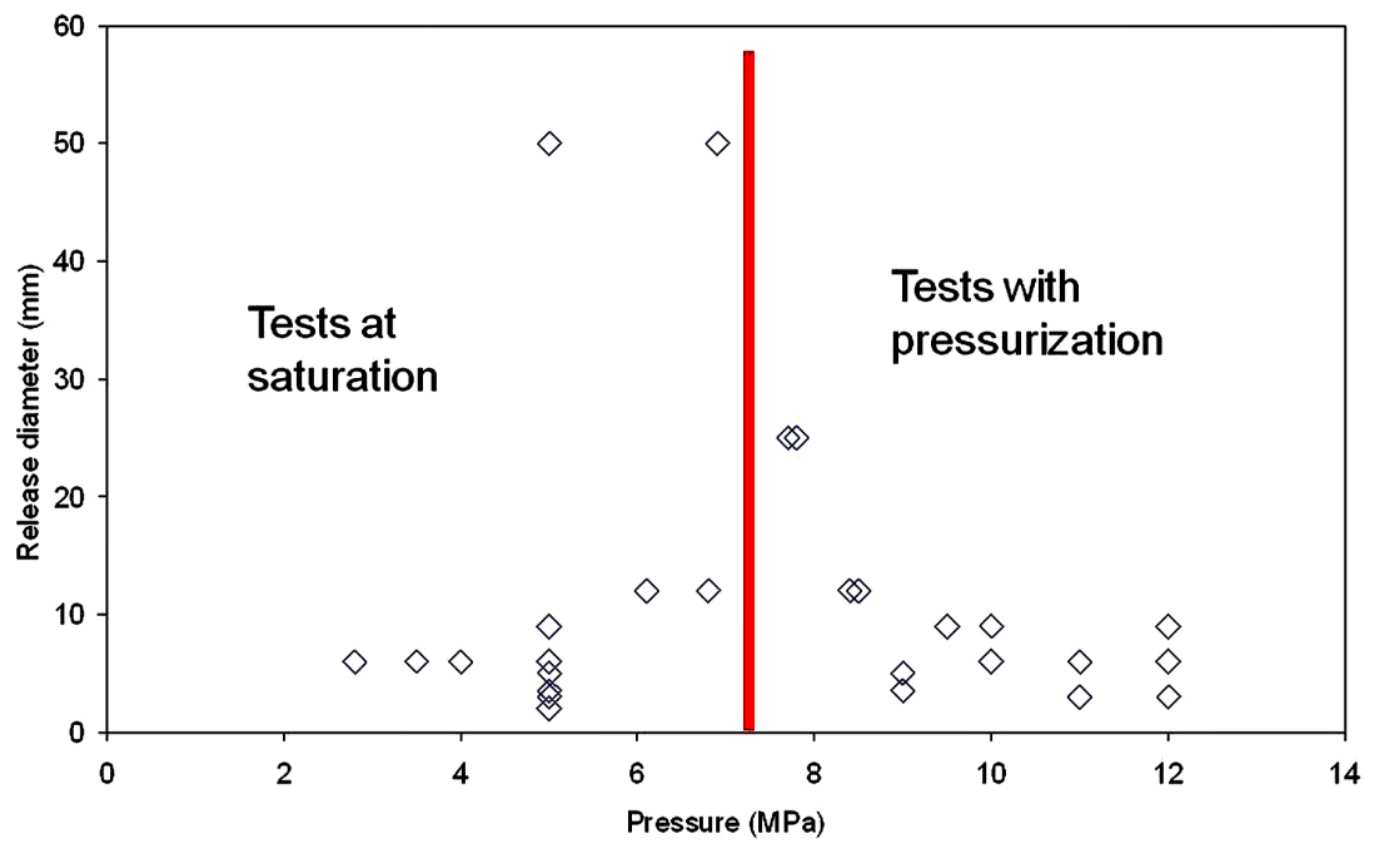

Figure 7 : Different tests conditions studied with this hardware

Besides the standard release configuration (horizontal free jet at 1.50 meter above ground), specific release configurations were studied: impacting jet, vertical or $45^{\circ}$ releases (Figure 8).

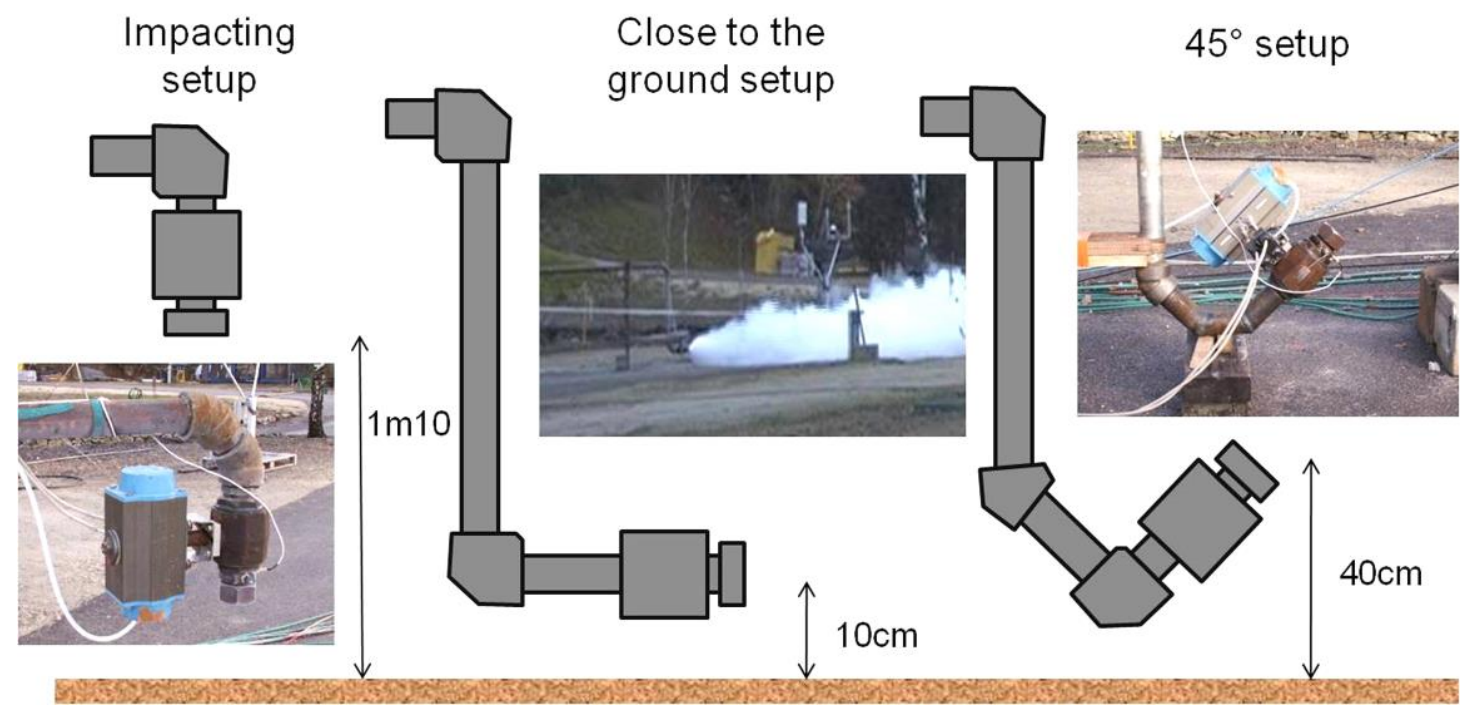

Figure 8 : Example of specific release setups as an alternative to horizontal straight jet 


\section{Instrumentation of the cloud}

\subsection{Nearfield}

A picture of the visual aspect of the jet, immediately downstream from the orifice (1 meter span) is shown on Figure 9. This is the expansion zone of the jet in which the pressure goes back to atmosphere inducing an outward expansion. The mixing zone with the outside air begins further downstream (see next section). The jet is optically thick suggesting the formation of tiny dry ice particles. It proved impossible to measure the size of those particles with known techniques like diffraction laser granulometry.
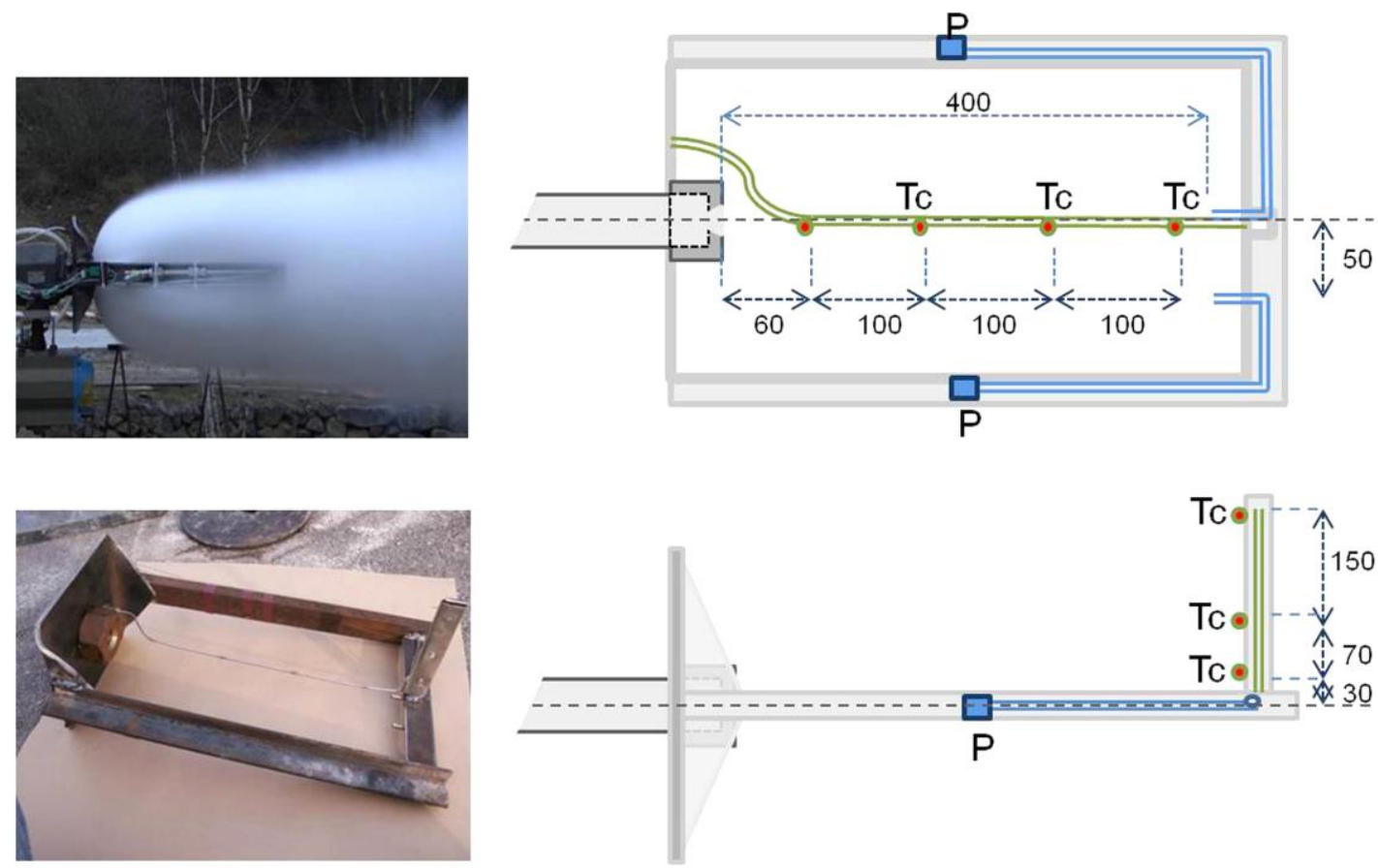

Figure 9 : example of $\mathrm{CO} 2$ release through a $25 \mathrm{~mm}$ hole. The release end is equipped with the sensor support (picture and sketches). $P$ is the location of the pressure sensor head. Tc is the junction of the thermocouples.

In order to investigate somehow this expansion zone, the local temperature and total pressure were measured between 0 and $400 \mathrm{~mm}$ from the orifice using the equipment shown on figure 9 (conceived to have the least influence as possible on the jet) : four $\mathrm{K}$ thermocouples $(1 \mathrm{~mm}$, class $\mathrm{A})$ were aligned on the axis of the jet and 3 others off axis. The total (over)pressure was measured on the axis and at some distance from the axis (KISTLER type $4045 \mathrm{~A} 2 ; 0-0.2 \mathrm{MPa} \pm 0,0002$ ). Because of the very abrasive nature of the jet and extremely low temperatures, the pressure transducers were maintained outside the jet and connected to small pipe toward the incoming flow. A particular attention has been paid to limit the impact of this equipment on the jet expansion.

A typical set of temperature measurements is presented on figure 10. Very low levels of temperature are reached (as low as $-100^{\circ} \mathrm{C}$ ), far below the expected $-78^{\circ} \mathrm{C}$ (sublimation point of dry ice at the atmospheric pressure). Such low levels, repeatedly observed need to be further investigated both theoretically (supersonic regimes) and experimentally since static electricity may be produced despite the precautions. 


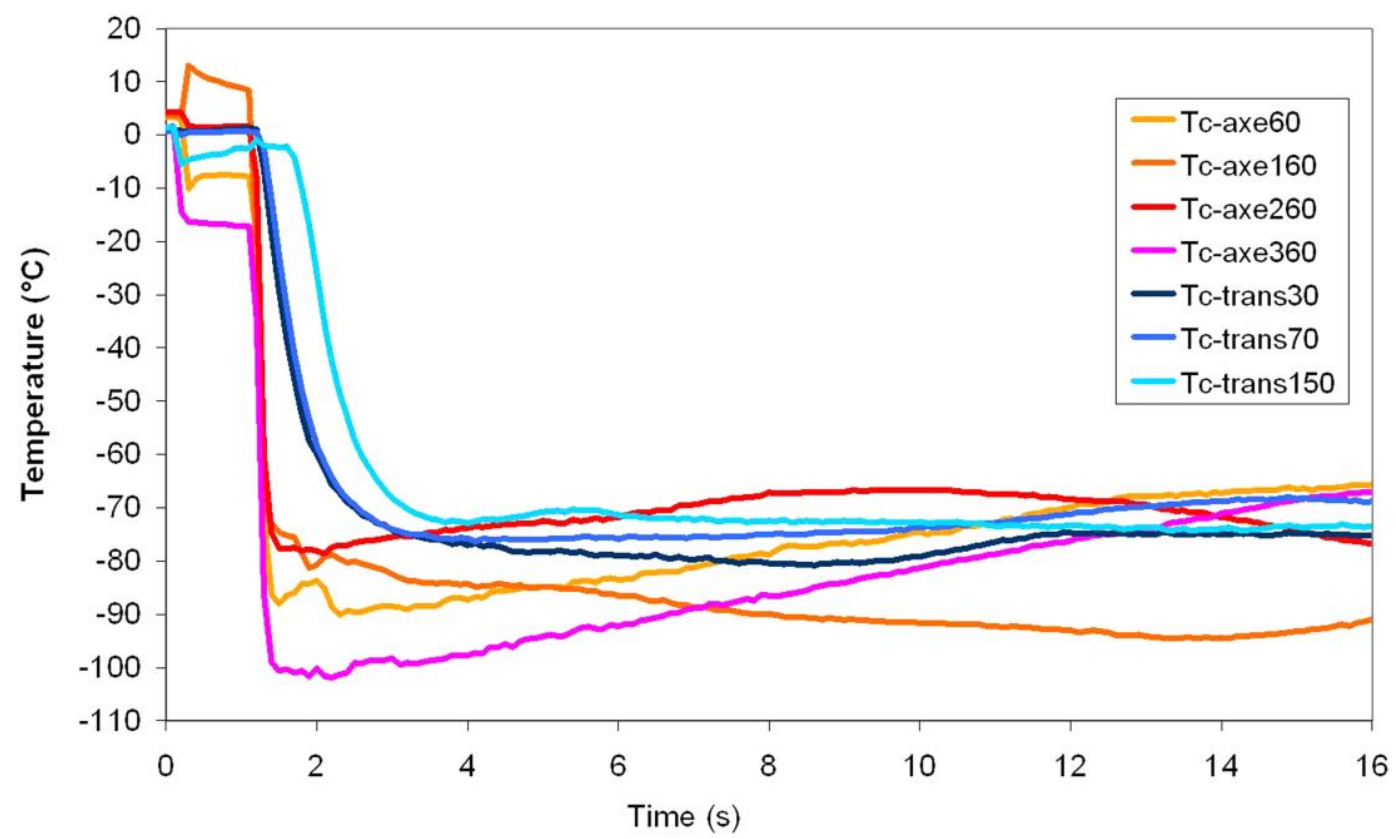

Figure 10 : Temperature measurements in the nearfield (the location of the T/C is given in the caption in mm)

Several jet behaviours were identified (Figure 11). In the early beginning of the release, the jet blows up violently. During this period, the mass flowrate varies rapidly and the pressure in the jet is significant $(0.1 \mathrm{MPa})$ justifying the observed diverging aspect of the flow. Later, the jet stabilises and remains identical in shape until complete blowdown. From about $150 \mathrm{~mm}$ to $500 \mathrm{~mm}$, the cross section of the jet is roughly constant suggesting that the flow lines are parallel. Because of this the static pressure in the jet should be equal to ambient so that the measured overpressure pressure should be equal to the local dynamic pressure.

These remarks can be used to obtain information about the characteristics of the jet. The mass flowrate, $\dot{m}$, the local dynamic pressure, $\mathrm{P}_{\mathrm{dyn}}$, and the apparent cross section of the jet $A_{j e t}$, are measured $\left(A_{\text {jet }}\right.$ from video). With this information, it is possible to deduce the average density, $\bar{\rho}$, and flow velocity $\bar{U}$ according to:

and

$$
P_{d y n}=\bar{\rho} \cdot \frac{\bar{U}^{2}}{2}
$$

$$
\dot{m}=\bar{\rho} \cdot \bar{U} \cdot A_{j e t}
$$

So that

$$
\bar{U}=\frac{2 \cdot P_{d y n} \cdot A_{j e t}}{\dot{m}}
$$

and

$$
\bar{\rho}=\frac{\dot{m}^{2}}{2 \cdot P_{d y n} \cdot A_{j e t}^{2}}
$$




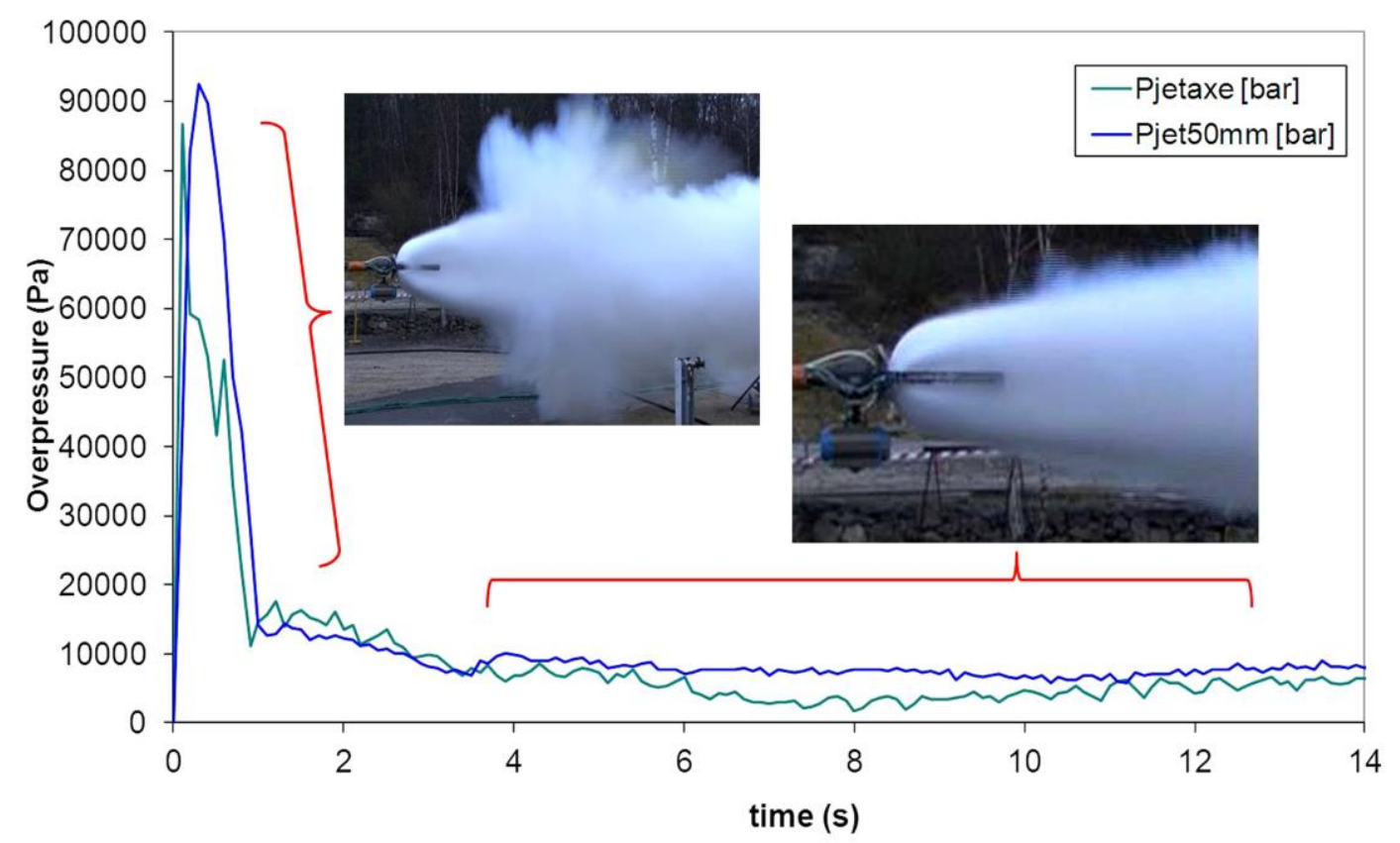

Figure 11 : Total (over)pressure measurements in the nearfield (the location of the pressure ports is given in the caption in $\mathbf{m m}$ )

Only rough estimations can be obtained (see results for two experiments in table 1) but the method is certainly robust. It comes out that the local density is significantly above that of the pure $\mathrm{CO}_{2}$ vapour at the (measured) local temperature (around $2,8 \mathrm{~kg} / \mathrm{m}^{3}$ ) implying that a significant fraction of dry ice is present (difference between measured density and pure gas density) as evidenced from the visual aspect of the jet. Figures obtained suggest that $40 \%$ to $50 \%$ in mass of condensed $\mathrm{CO}_{2}$ is present. The velocity seems also significantly lower than at the orifice (estimated value around $110 \mathrm{~m} / \mathrm{s}$ ) which is only possible if a strong condensation occurs.

Table 1

\begin{tabular}{|c|c|c|c|c|c|c|c|c|}
\hline $\begin{array}{c}\text { test } \\
\mathrm{n}^{\circ}\end{array}$ & $\begin{array}{c}\text { Temperature } \\
\text { fluide }\left({ }^{\circ} \mathrm{C}\right)\end{array}$ & $\begin{array}{c}\mathrm{P}_{\text {sphere }} \\
(\mathrm{MPa})\end{array}$ & $\begin{array}{c}\dot{m} \\
(\mathrm{~kg} / \mathrm{s})\end{array}$ & $\begin{array}{c}\mathrm{P}_{\text {dyn }} \\
(\mathrm{Pa})\end{array}$ & $\begin{array}{c}\mathrm{A}_{\text {jet }} \\
\left(\mathrm{m}^{2}\right)\end{array}$ & $\begin{array}{c}\text { Temperature } \\
\text { at } 360 \mathrm{~mm}\left({ }^{\circ} \mathrm{C}\right)\end{array}$ & $\begin{array}{c}\rho \\
\left(\mathrm{kg} / \mathrm{m}^{3}\right)\end{array}$ & $\begin{array}{c}\mathrm{U} \\
(\mathrm{m} / \mathrm{s})\end{array}$ \\
\hline 1 & 5 & 7,8 & 23,4 & 6000 & 0.10 & -85 & 4,9 & 49 \\
\hline 2 & 9 & 7,0 & 37,6 & 6000 & 0.14 & -80 & 5,6 & 46 \\
\hline
\end{tabular}

\subsection{Farfield and plume}

The entrainment of the outside air starts at the end of the expansion zone. It is manifested on the videos by the formation of a faint boundary layer surrounding the central jet. A plume is produced downstream and the spatial distribution of the carbon dioxide is to be investigated as well as the relative roles of the various potential "mixing mechanisms": momentum, wind, body forces. The momentum could be estimated with the device presented in the previous section. To investigate the incidence of the body forces the density of the mixture needs to be known. The latter is a direct function of the local concentration and temperature (using for instance the perfect gas law). 
It is quite straightforward to estimate the thermal energy exchanged between the $\mathrm{CO}_{2}-$ air plume and the surroundings. The amount of energy, $\mathrm{P}_{\mathrm{air}}$, exchanged by unit of time between the $\mathrm{CO}_{2}$ and the entrained air, at a given position, $x$, inside the plume reads :

With :

$$
P_{\text {air }}=\dot{m} \cdot C p_{\mathrm{CO} 2} \cdot\left(T_{m}-T_{\mathrm{CO}_{2}}\right)+\dot{m} \cdot y_{\mathrm{CO}_{2}} \cdot L_{\mathrm{CO} 2}
$$

$C p_{\mathrm{CO}_{2}} \quad \mathrm{CO}_{2}$ specific heat,

$T_{m} \quad$ Temperature measured at a given position, $x$, in the plume,

$T_{\mathrm{CO}_{2}}$ Temperature of the $\mathrm{CO}_{2}$ at the end of the expansion zone,

$y_{\mathrm{CO}_{2}}$ Mass fraction of condensed $\mathrm{CO}_{2}$ at the end of the expansion zone,

$\mathrm{L}_{\mathrm{CO}_{2}} \quad$ Latent heat of condensation (vapor to solid) for $\mathrm{CO}_{2}$

The amount of energy exchanged by convection with the ground, $P_{\text {sol }}$, reads :

$$
P_{\text {sol }}=h \cdot x \cdot \phi \cdot \frac{T_{m}-T_{\mathrm{CO}_{2}}}{2}
$$

With :

$h \quad$ Convective heat transfer coefficient

$\phi \quad$ Mean width of the cloud along length $x$

And the amount of energy exchanged by radiation, $P_{\text {ray }}$, is approximately:

$$
P_{\text {ray }}=\sigma_{o} \cdot \phi^{2} \cdot x \cdot\left(T_{m}^{4}-\left(\frac{T_{m}+T_{C_{2}}}{2}\right)^{4}\right)
$$

Assuming a coefficient of emissivity equal to 1 (i.e. $\sigma=\sigma_{o}$ )

A numerical application is proposed in table 2. For a typical release $(12 \mathrm{~mm}$ diameter, 70 bar) the shape of the cloud ( $x$ and $\phi$ ) at $2 \% \mathrm{v} / \mathrm{v} \mathrm{CO}_{2}$ threshold has been estimated on the basis of preliminary measurements (sampling and analysis). The mass fraction of solid $\mathrm{CO}_{2}$ at the end of the expansion zone has been set to $40 \%$ following results of 3.1 .

Table 2 Estimation of exchanged amount of energy during the formation of the plume

\begin{tabular}{|c|c|}
\hline $\mathrm{CO}_{2}$ mass flowrate $(\mathrm{Kg} / \mathrm{s})$ & 8 \\
\hline$y \mathrm{cO} 2$ & 0.4 \\
\hline$T_{\mathrm{m}}\left({ }^{\circ} \mathrm{C}\right)$ at $2 \% \mathrm{v} / \mathrm{VO} \mathrm{CO}_{2}$ threshold & -3 \\
\hline$x(\mathrm{~m})$ at $2 \% \mathrm{v} / \mathrm{CO} \mathrm{CO}_{2}$ threshold & 30 \\
\hline$\phi(\mathrm{m})$ at $2 \% \mathrm{v} / \mathrm{v} \mathrm{CO}{ }_{2}$ threshold & 4 \\
\hline$P_{\text {air }}$ & $1600000 \mathrm{~W}$ \\
\hline$P_{\text {sol }}$ & $5000 \mathrm{~W}$ \\
\hline$P_{\text {ray }}$ & $70000 \mathrm{~W}$ \\
\hline Contribution of $P_{\text {sol }}$ and $P_{\text {ray }}$ & $4.4 \%$ \\
\hline
\end{tabular}


Thus, with a very good level of approximation (less than 5\% accuracy up to a dilution of $2 \%$ ), it can be admitted that the mixing process between the cold $\mathrm{CO}_{2}$ emerging from the orifice and the "hot" surroundings air is adiabatic. Hence, any temperature gap (from ambient) in the plume should result from the adiabatic mixture of some cold $\mathrm{CO}_{2}$ forms in the expansion zone with the outside air mixture.

Following, a thermal balance (enthalpy) can be established between the exit of the expansion zone and the measuring point. Depending on ambient conditions practically all the water contained in the atmosphere will condense in the jet, contributing to the thermal balance to a large extent. However, as water represents far less than $2 \%$ in mass in the ambient air, the plume can be treated as a mixture of dry air in $\mathrm{CO}_{2}$, permitting some simplifications. It is assumed that, in the farfield where the local temperature is much larger than $-80^{\circ} \mathrm{C}$, all the solid $\mathrm{CO}_{2}$ is sublimed:

$$
C=\frac{C p_{a i r} \cdot\left(T_{a m b}-T_{m}\right)+y_{H 2 O} \cdot\left[C p_{H 2 O} \cdot\left(T_{a m b}-T_{m}\right)+L_{H 2 O}\right]}{\left[C p_{C O 2} \cdot\left(T_{m}-T_{C O 2}\right)+y_{C O 2} \cdot L_{C O 2}\right]+C p_{a i r} \cdot\left(T_{a m b}-T_{m}\right)+y_{H 2 O} \cdot\left[C p_{H 2 O} \cdot\left(T_{a m b}-T_{m}\right)+L_{H 2 O}\right]}
$$

With :

$C p_{\text {Air }}$ Air specific heat,

$\mathrm{Cp}_{\mathrm{CO}_{2}} \mathrm{CO}_{2}$ specific heat,

$T_{a m b}$ Ambient temperature of the outside atmosphere,

$T_{m} \quad$ Temperature measured at the sampling point in the plume,

$T_{\mathrm{CO}_{2}}$ Temperature of the $\mathrm{CO}_{2}$ at the end of the expansion zone $\left(100 \% \mathrm{CO}_{2}\right)$,

$y_{\mathrm{H}_{2} \mathrm{O}}$ Mass fraction of air humidity which should be condensed at Tm (equilibrium),

$L_{\mathrm{H}_{2} \mathrm{O}}$ Latent heat of condensation for water,

$L_{\mathrm{CO}_{2}}$ Latent heat of condensation (vapor to solid) for $\mathrm{CO}_{2}$,

$y_{\mathrm{CO}_{2}}$ Mass fraction of condensed $\mathrm{CO}_{2}$ at the end of the expansion zone

Obviously, it is much easier to measure temperature than sampling the atmosphere to perform a chemical analysis. Thermocouples can be used which are fast enough, robust, easy to check and can be used in numbers. In practice, stainless steel housing $\mathrm{K}$ thermocouples were used with an extremity size of $0.5 \mathrm{~mm}$ so that response time is better than $1 \mathrm{~s}$ enabling a dynamic analysis of the plume.

However, to be able to use the correlation in a predictive way, it is necessary to choose a value for $\mathrm{T}_{\mathrm{CO} 2}$ and $\mathrm{y}_{\mathrm{CO} 2} . \mathrm{CO}_{2}$ sublimation temperature at ambient pressure $\left(-78^{\circ} \mathrm{C}\right)$ appears as a reasonable value for $\mathrm{T}_{\mathrm{CO} 2}$. Nearfield temperature measurements confirmed this order of magnitude and sensitivity tests (in a range of $-/+10^{\circ} \mathrm{C}$ ) proved only a slight influence on the concentration.

The $\mathrm{CO}_{2}$ solid mass fraction is more difficult to estimate. Nearfield estimation is not accurate enough. To overcome this difficulty, the $\mathrm{CO}_{2}$ concentration was measured at a few points together with the temperature. To do this, paramagnetic oxygen analysers (SERVOMEX - type PM1158 - error $\pm 0.02 \% \mathrm{O}_{2} \mathrm{v} / \mathrm{v}$ ) were used. The $\mathrm{CO}_{2}$ concentrations can readily be deduced from the $\mathrm{O}_{2}$ concentration with a limited absolute error (lower than $\pm 1 \% \mathrm{CO}_{2}$ ). The measurement points are chosen sufficiently far to be sure that all the $\mathrm{CO}_{2}$ is sublimed. $\mathrm{yCO}_{\mathrm{CO}}$ is chosen in such a way that the 
concentration deduced from the temperature readings coincides with the "direct" measurement (from $\% \mathrm{O}_{2}$ ). For a large panel of test conditions a very good level of correlation was obtained with $\mathrm{y}_{\mathrm{CO} 2}=0.30$ (Figure 12). This value is deemed much more reliable that the estimations of $\$ 3.1$, but remains in the same order of magnitude.

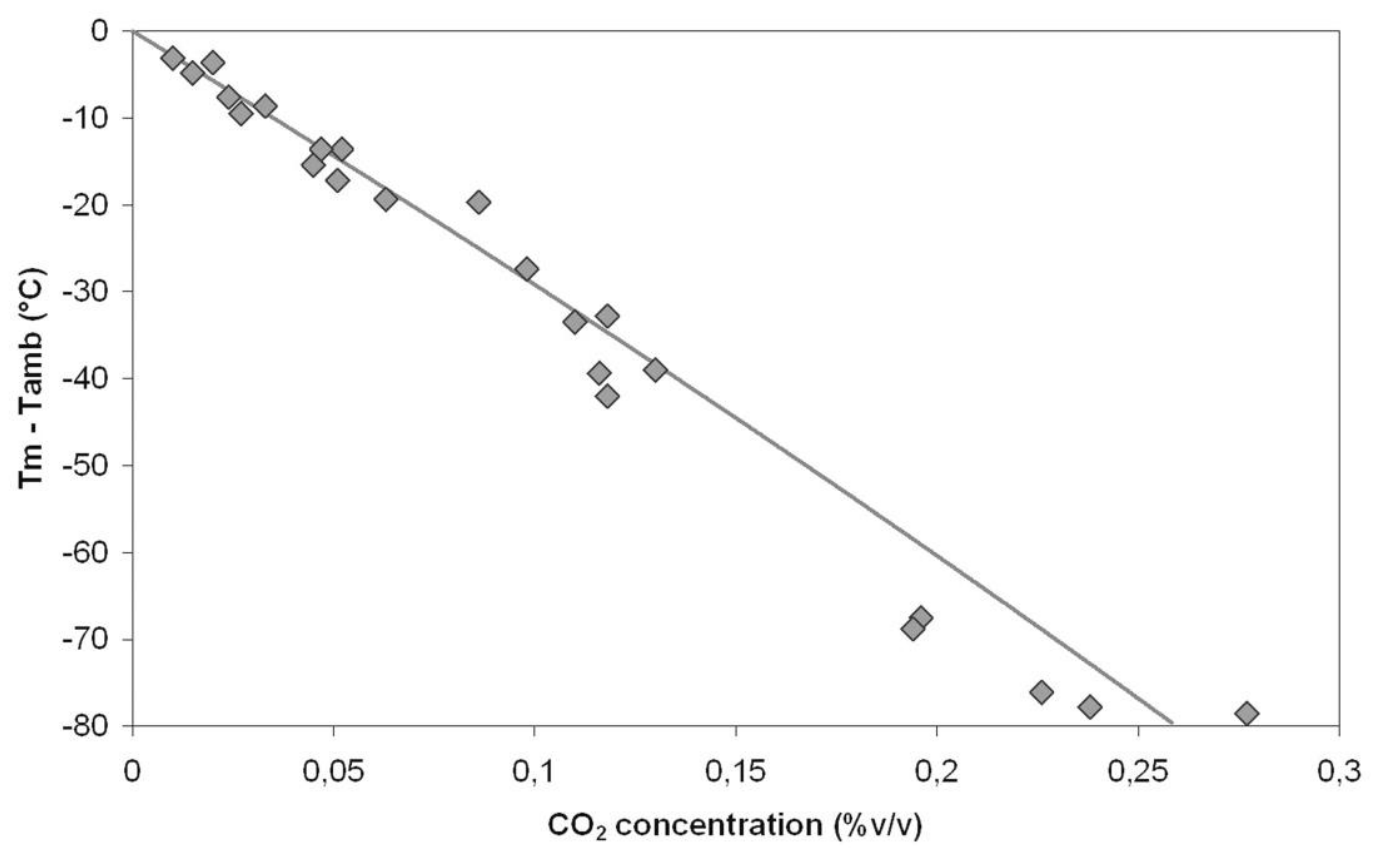

Figure 12 : Temperature versus $\mathrm{CO}_{2}$ concentration in the plume (curve corresponding to the theoretical correlation with $\mathbf{y}=\mathbf{0 . 3}$ )

Figure 13 illustrates a typical arrangement of 26 thermocouples distributed along 6 masts. One $\mathrm{O}_{2}$ sampling line is attached on each mast and the sampling point is located on the axis of the leakage, 1.5 meter above the ground.

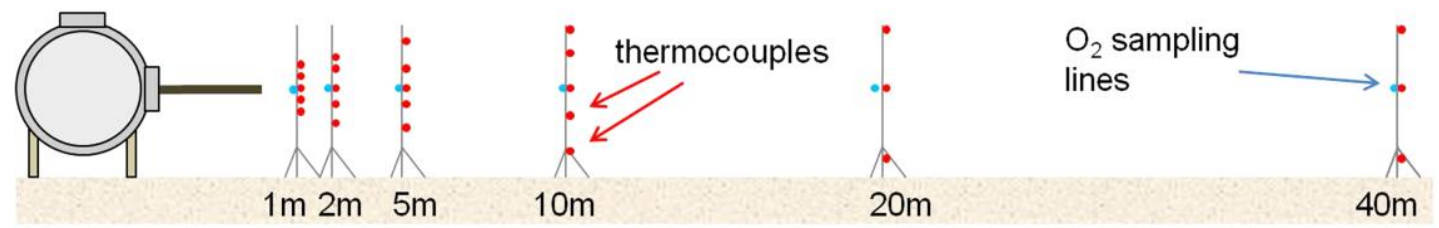

Figure 13 : schematic of the arrangement of the masts and transducers.

The local environmental conditions (wind speed, temperature and humidity) are controlled during each test. In order to be sure that the plume could cross the instrumentation field most tests were performed in nearly no wind conditions (less than $0.2 \mathrm{~m} / \mathrm{s}$ ). The distribution of the $\mathrm{CO}_{2}$ concentration inside the plume was deduced from the temperature signals. A typical example is presented in figure 14. The isoconcentration curves diagram is approximately on the same scale as the picture. It can be appreciated that the visible cloud encompasses the "dangerous" zone but is significantly larger. The visible border seems to correspond to the dew point of the atmosphere (90\% air humidity in this example) and corresponds to a concentration of $\mathrm{CO}_{2}$ smaller than $0.5 \% \mathrm{v} / \mathrm{v}$. 


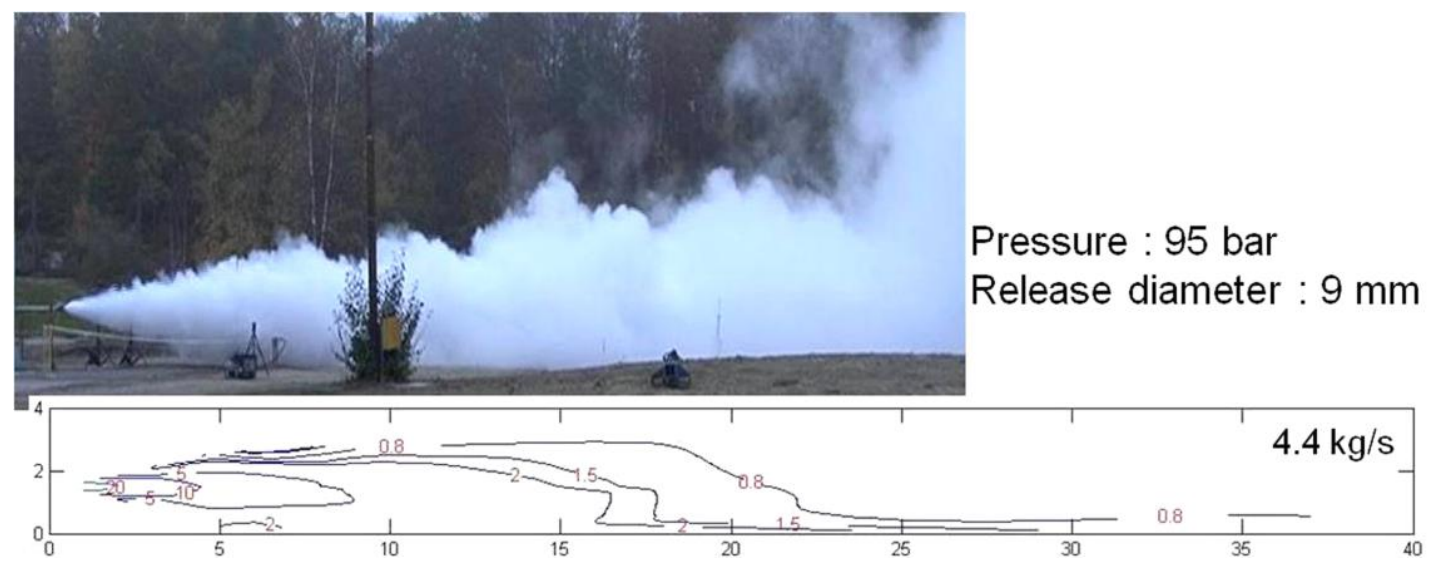

Figure 14 : picture extracted from video together with isoconcentration lines (in \%v/v) calculated from temperature mesh (same reference time).

The impact of the mass flowrate can be estimated (Figure 15). It appears that the cloud tends to fall down at least after ten meters from the leakage point suggesting an incidence of the body forces. The incidence is hardly visible at $4.5 \mathrm{~kg} / \mathrm{s}$ but is clear above $8 \mathrm{~kg} / \mathrm{s}$.

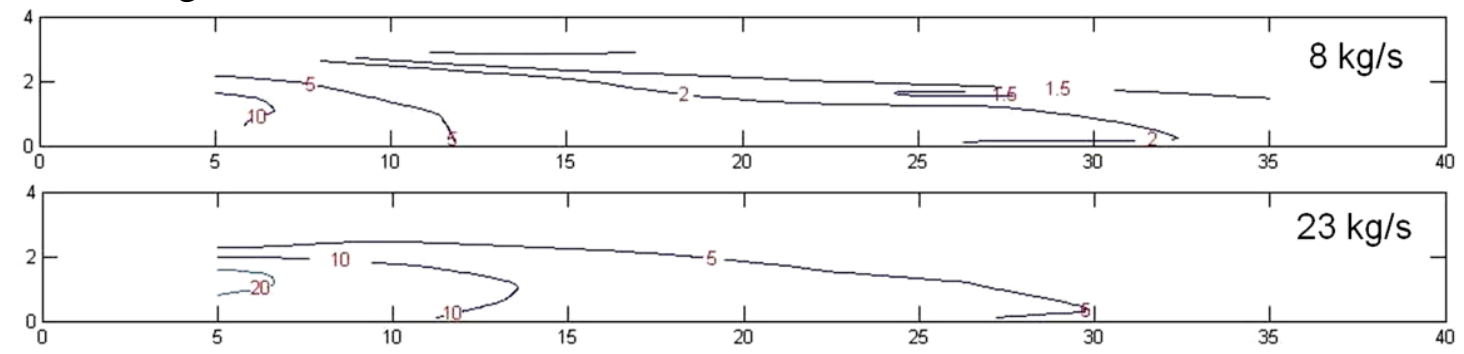

Figure 15 : isoconcentration lines (in \%v/v) for two other releases

\section{Conclusions}

In this paper, an experimental setup is described aiming at studying the dispersion of massive releases of $\mathrm{CO}_{2}$ into the atmosphere (from about $10 \mathrm{MPa}$ in dense phase). To perform the experiments, an instrumented (internal temperature and pressure) $2 \mathrm{~m}^{3}$ vessel connected to a 2" inner diameter pipe was used. The mass flowrate was measured directly by weighing continuously the vessel. Calibrated orifices were used ranging from $2 \mathrm{~mm}$ to full bore $(50 \mathrm{~mm})$. A specific device was designed to measure the temperatures and pressures in the expansion zone of the jet in order to investigate the expansion zone. To investigate the plume, an original and simple technique was devised to obtain both the $\mathrm{CO}_{2}$ concentration and density distribution.

Present data suggest that a significant portion of $\mathrm{CO}_{2}$ (30\% in mass) is solidified in the expansion zone. Apparently, this "cryo freezing" process was so fast that only very small particles could be formed explaining why accumulation of dry ice wasn't observed whatever the release conditions. The mixing in the cloud is reasonably adiabatic enabling a significant reduction of the temperature so that body forces appear and seem to be significant even at a rather low flowrate (above $8 \mathrm{~kg} / \mathrm{s}$ and dominating above $23 \mathrm{~kg} / \mathrm{s}$ ). 


\section{References}

[1] Eos, Transactions, American Geophysical Union 2004, Vol. 85, No. 30, 27, 281288.

[2] C. J. Warein, R. M. Woolley, M. Fairweather, S. A. E. G. Falle, AIChE J. 2013, $59,10,3928-3942$.

[3] National Institute for occupational Safety and Health (NIOSH), 1996, "Documentation for Immediately Dangerous to Life or Health Concentrations (IDLHs) for Carbon Dioxide" <www.cdc.gov> accessed 01.02.2014.

[4] S. Brown, S. Martynov, H. Mahgerefteh, C. Proust, Int. J. Greenh. Gas Con. 2013, (to appear).

[5] R. M. Woolley, M. Fairweather, C. J. Wareing, S. A. E. G. Falle, C. Proust, J. Hebrard, D. Jamois, Int. J. Greenh. Gas Con. 2013, 18, 1, 139-149.

[6] M. Ahmad, L. Buit, O. Florisson, C. Hulsbosch-Dam, M. Bögemann-van Osch, M.Spruijt, F. Davolio, Energy Procedia 2013, 37 3005-3017.

[7] R. Cooper, National Grid's COOLTRANS research programme, Journal of Pipeline Engineering 2012, 11, 155-172.

[8] M. Pursell, Proc. IChemE Hazards XXIII Conference 2012, Southport, UK, 12-15.

[9] CO2Pipehaz - "Quantitative Failure Consequence Hazard Assessment for Next Generation $\mathrm{CO}_{2}$ Pipelines : The Missing link" 2009, EU, - <www.CO2pipehaz.eu> accessed 01.02.2014. 